Article

\title{
Creating a Pharmacotherapy Collaborative Practice Network to Manage Medications for Children and Youth: A Population Health Perspective
}

\author{
Richard H. Parrish II ${ }^{1,2, * \mathbb{C}}$, Danielle Casher ${ }^{3}$, Johannes van den Anker ${ }^{4,5,6}$ and \\ Sandra Benavides ${ }^{7}$ \\ 1 Department of Pharmacy Services, St. Christopher's Hospital for Children-American Academic Health \\ System, 160 East Erie Avenue, Philadelphia, PA 19134, USA \\ 2 School of Pharmacy, Virginia Commonwealth University, Richmond, VA 23298, USA \\ 3 Department of Pediatrics, Drexel University College of Medicine, Philadelphia, PA 19134, USA; \\ danielle.casher@americanacademic.com \\ 4 Universitäts-Kinderspital beider Basel (UKBB), Spitalstrasse 33, CH-4031 Basel, Switzerland; \\ JohannesN.VandenAnker@ukbb.ch \\ 5 Children's National Health System, 111 Michigan Avenue, Washington, DC 20010, USA \\ 6 Erasmus Medical Center-Sophia Children's Hospital, s-Gravendijkwal 230, 3015 CE Rotterdam, \\ The Netherlands \\ 7 PRIME Education, Fort Lauderdale, FL 33309, USA; sandra.b.caballero@gmail.com \\ * Correspondence: Richard.Parrish@AmericanAcademic.com; Tel.: +1-215-427-5317
}

Received: 22 February 2019; Accepted: 3 April 2019; Published: 9 April 2019

\begin{abstract}
Children with special health care needs (CSHCN) use relatively high quantities of healthcare resources and have overall higher morbidity than the general pediatric population. Embedding clinical pharmacists into the Patient-Centered Medical Home (PCMH) to provide comprehensive medication management (CMM) through collaborative practice agreements (CPAs) for children, especially for CSHCN, can improve outcomes, enhance the experience of care for families, and reduce the cost of care. Potential network infrastructures for collaborative practice focused on CSHCN populations, common language and terminology for $\mathrm{CMM}$, and clinical pharmacist workforce estimates are provided. Applying the results from the CMM in Primary Care grant, this paper outlines the following: (1) setting up collaborative practices for CMM between clinical pharmacists and pediatricians (primary care pediatricians and sub-specialties, such as pediatric clinical pharmacology); (2) proposing various models, organizational structures, design requirements, and shared electronic health record (EHR) needs; and (3) outlining consistent documentation of CMM by clinical pharmacists in CSHCN populations.
\end{abstract}

Keywords: clinical pharmacist; pediatrician; clinical pharmacology; pharmacotherapy; comprehensive medication management; pediatric medicines; special needs; collaboration; children; care networks

\section{Introduction and Statement of Need}

U.S. children's hospitals and health systems have identified a lack of a standard definition for children with special health care needs (CSHCN). A lack of consensus may diminish the effectiveness of improvement projects designed to address social determinants of health in children, especially CSHCN and/or those with medical complexity (CMC) [1]. According to the Maternal and Child Health Bureau of the Health Resources and Services Administration (HRSA), CSHCN is defined as children and youth that "have or who are at risk for chronic physical, developmental, behavioral, or emotional conditions, 
and who also require health and related services of a type or amount beyond that by children generally." Nearly $20 \%$ (or 17 million) of children under the age of 18 have at least one special need [2]. CMC, a sub-population of approximately 3 million, require the highest level of services and support due to their care intensity and the breadth of pediatric sub-specialists required [3]. This CMC sub-population is growing in terms of resource utilization, and requires policy and programmatic interventions that differ from broader CSHCN groups. Systems of care for CMC should be informed through evidence-based solutions to the ongoing challenges of caring for $\mathrm{CMC}$ with better sub-population definitions, especially in the areas of community care and outcomes measurement [4-7]. Qualitative themes have emerged in defining the population health of $\mathrm{CMC}$, including health optimization and outcome measurement, and the importance of family and social determinants [8]. For community primary care providers (PCPs), patient and drug regimen characteristics such as polypharmacy, multi-organ system involvement, and rare/unfamiliar diagnoses often negatively affect care. In addition, caregivers with high needs, time constraints during visits, and challenges with care coordination were also frequently cited as impairing good clinical outcomes [9]. Key challenges are reported to be development of a consensus method to identify CMC, promotion of high-quality research, navigation of health care reform, and measures to promote professional identity and workforce development [7].

Within the evolving programs and systems of care for CSHCN and CMC, there is a need for better medication management processes and systems to aid in the coordination and quality of care received, especially during transitions of care and in the home environment [7,9-12]. While pediatric patients and their drug therapy needs, in general, are very different from adults, there are structures and processes of care that can be universally applied regardless of patient population. Among these are comprehensive medication management $(\mathrm{CMM})$ within the structure of collaborative practice agreements (CPAs) between clinical pharmacists and physicians, such as those which have been successfully developed and implemented in adult primary care practices, associations, and health systems [13].

The overall purpose of this concept paper is to address the need for and creation of a pharmacotherapy collaborative practice network through CPAs for CMM in children and youth populations. In addition, this paper outlines the following: (1) organizing a collaborative practice for CMM between a clinical pharmacist and a pediatrician (primary care pediatricians and sub-specialties, such as pediatric clinical pharmacology); (2) describing and proposing various models, organizational structures, design requirements, and shared electronic health record (EHR) needs; and (3) outlining consistent documentation of CMM by clinical pharmacists in CSHCN populations.

\section{Children with Special Health Care Needs and Medical Complexity (CSHCN and CMC)}

\subsection{Current Models of Care Delivery}

There are three current models of care for CMC: (1) primary care-centered models; (2) consultativeor co-management-centered models; and (3) episode-based models. While these models have been evaluated favorably, they lack generalizability since standardized outcomes and population definitions for CMC are lacking. Collaboration among patients, families, providers, payers, and policy makers is required to identify gaps in care and build high reliability guidelines [6]. CMC models need to encompass comorbid neurodevelopmental conditions that frequently accompany outpatient encounters [14]. For example, CMC with upper and lower respiratory tract and gastrointestinal conditions are being treated through multidisciplinary aerodigestive centers at tertiary care centers, and integration of a general pediatrician can promote a whole-person Patient Centered Medical Home (PCMH) [15]. One report described an overarching theme "unsung heroes, flying blind" that illustrate aspects of the parents' experience in caring for CSHCN and CMC. The enormous burden of care can decrease the parents' ability to provide care, and impact the parents' health, family functioning and the sick child's potential health outcomes [16]. Comprehensive care oversight may improve care coordination but not health status for parents of CMC [17]. 


\subsection{Population Health Aspects of the Patient-Centered Medical Home (PCMH)}

In Figure 1, Kindig has provided a conceptual framework for understanding population health $(\mathrm{PH})$, which can be applied to CSHCN and focus on both determinants of care and outcomes. Population health is defined as the "the health outcomes of a group of individuals, including the distribution of such outcomes within the group" [18].

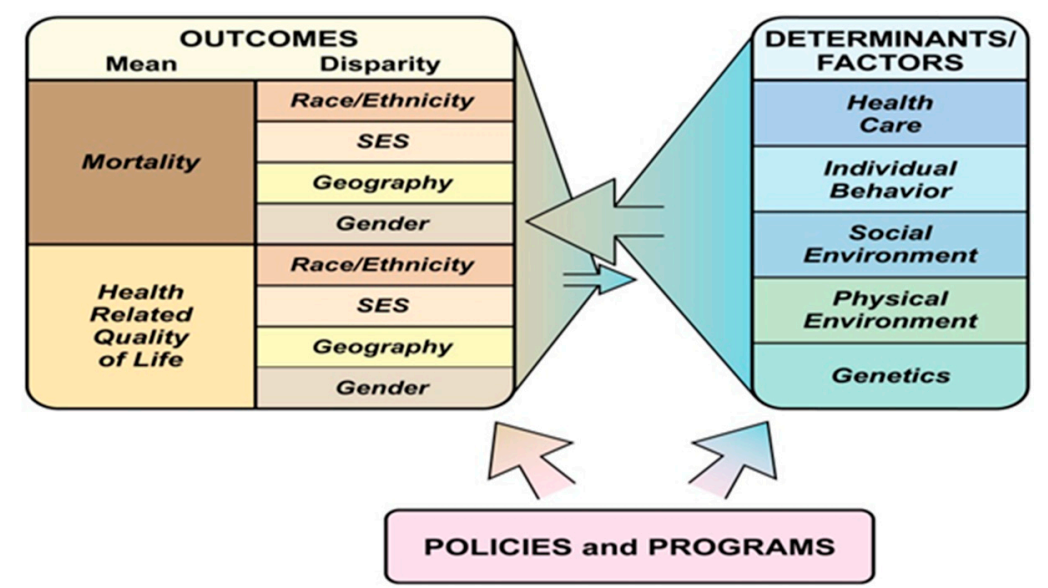

Figure 1. What is population health? [13].

Population health management (PHM) approaches to improve cost and quality have included an operating model which incorporates: "(1) a multi-layered, interprofessional infrastructure; (2) data dashboards to guide continuous quality improvement; (3) revamped provider payments; (4) consumer spending accounts; and (5) incentive alignment for shared savings with practices." One mechanism for improving the organization and delivery of health care to populations, in general, and for CSHCN-CMC, in particular, is the Patient Centered Medical Home (PCMH) [19]. PCMH is not a place, but a model for primary care delivery encompassing comprehensive care, patient centeredness, coordinated care, accessible services, and quality and safety [20]. Primary care practices face many barriers to providing PCMH care to patients with complex needs. Reported barriers include the organization's structure, lack of resources such as staff, space, and technology, and communication between health care team members [21]. Innovative programs that focus on patients with high resource utilization, place case managers in primary care practices, allow flexibility in matching staff to the needs of each practice, and help primary care clinicians manage $\mathrm{CMC}$ alongside regular patients improve care for CMC. More support is needed for smaller primary care practices to become effective PCMHs for CMC. Increased reimbursement is necessary for practices to have the resources to serve CMC effectively and to support programs that collaborate with primary care practices. Further research is required to delineate delivery models that will succeed in different types of communities [22]. Data from the 2016 National Survey of Children's Health ( $\mathrm{N}=50212)$ indicated that $43.2 \%$ of $\mathrm{CSHCN}$ and $50 \%$ of otherwise healthy children have access to a medical home. Attainment of the Medical Home Composite Measure, as measured by the National Survey of Children's Health, is defined by five subcomponents including a usual source of care, having a personal physician or nurse, receiving needed referrals, receiving coordinated care, and receiving family-centered care varied significantly by sociodemographic characteristics among both CSHCN and non-CSHCN, as did attainment rates for each of the five subcomponents [23].

CSHCN with broad functional impairment (physical, cognitive, and mental health) demonstrated the highest emergency department (ED) utilization, highest odds of hospitalization, and lowest odds of a having a medical home [24]. CSHCN with functional limitations may have poorer health status and more complex health care needs, and more often experience a variety of health issues due to inadequate insurance, increased impact of health conditions on the family, and higher medical costs [25]. A third of families of CSHCN, predominantly with children from racial/ethnic minority backgrounds, those in poverty, and those with complex emotional/ behavioral or developmental needs and functional 
limitations, are reported to encounter difficulties, delays, or frustrations in obtaining health and related services [26,27]. Unmet needs in CMC may be double that of those without medical complexity [28]. PCMHs exist often in primary care practices, since these pediatricians are more comfortable than specialist pediatricians in providing a medical home for a child with chronic medical or developmental conditions $[29,30]$.

In one study, CMC had a mean of 19 annual outpatient visits (USD \$616) and one in four had inpatient visits (\$3308), with other significant cost drivers including home health (\$2957) and prescription medications (\$2182). The main reasons for CMC visits were for mental health [31]. Compared to families without CSHCN, those with CMC have, on average, lower satisfaction with health care. Total spending increases for children with chronic conditions might be due to an increase in the number of recipients with the most complex chronic conditions, not increased per member per month payment to primary care providers [31]. The presence of multiple extracardiac co-morbidities is often associated with higher resource utilization following the index cardiac surgical procedure [32]. As qualifiers for special needs status among American Indian/Alaska Native (AIAN) children, the use of or need for prescription medication was the most frequent, and significantly greater disease burden among AIAN CSHCN suggests that care must be taken to ensure an appropriate level of coordinated care in a medical home to ameliorate the severity and complexity of their conditions [11].

\subsection{Youth with Special Health Care Needs (YSHCN)}

Youth with Special Heath Care Needs (YSHCN), aged 12-17 years, represent a unique sub-population of CSHCN, and a majority may have three or more comorbid conditions. Efforts for this sub-population should focus on strengthening coordinated systems of care that optimally meet the needs of YSHCN so they may thrive in their families and communities [10]. Only one-third of YSHCN had adequate transition to adult care preparation (care coordination, shared decision making, and family-centered care), and the majority that lack it are male adolescents with medical complexity [33]. One recent example of a hospital-based transition preparation infrastructure included five core objectives: "(1) facilitating medical transition with a focus on structure and processes; (2) assessing current transition policy/practice at baseline; (3) communicating the complexity and necessity of transition planning; (4) mobilizing adult providers to champion transition planning for YSHCN; and (5) identifying methods to analyze transition program building activities" [34]. PCMH can encompass such strategies in developing programs to transition YSHCN to adult care.

\subsection{Behavioral Health}

Neurodevelopmental conditions affect $\sim 15 \%$ of US children, and the prevalence and complexity of these conditions are increasing. The workforce struggles to meet current service demands, with long waiting times for appointments, increased complexity, and high volumes of non-reimbursed care. Sustaining the subspecialty will require strategies to maintain and expand the workforce, improve clinical efficiency, and prevent burnout [35]. Older children and those living in poorer households were more likely to have an unmet need for behavioral healthcare services among CSHCN with CMC. The prevalence of unmet mental healthcare needs among both groups increased during 2005-2010 [36]. An important component of behavioral health PCMH is shared decision making (SDM), which engages the patient or caregiver in medical decisions based on the values, preferences and treatment goals of the patient or caregiver. For younger children, parents are usually involved in SDM. However, with older children and adolescents, attention deficit/hyperactivity disorder (ADHD) and/or autism spectrum disorder (ASD), most of the SDM processes involve the parent [37]. While future strategies should be implemented to incorporate the child or adolescent as appropriate, challenges due to cognitive abilities in children with CSHCN may hamper effective SDM [38]. 


\subsection{Quality/Continuity of Care/Care Coordination}

Care coordination is defined by the Agency for Healthcare Research and Quality (AHRQ) as "optimally organizing patient care and information-sharing activities" [39]. Coordination is an important aspect of high quality, patient-centered care. It improves safety, effectiveness, and efficiency of health care provided. Measures of coordination processes must be robust for generating evidence about its outcomes, analyzing existing practices, developing quality improvement activities, and supporting targeted payment initiatives. Continuity of care holds promise as a quality measure for CMC because of its association with lower ED utilization and more frequent receipt of care coordination [40]. Recently, the Family Experience with Coordination of Care assessed the quality of coordination as reported by the caregiver [41]. The Post-Acute Acuity Rating for Children, intended to reflect medical severity based on age, reason for admission, diagnoses, dependence in activities of daily living, and technology reliance for children admitted to post-acute care rehabilitation hospitals, has been found to be a comparable measurement of medical complexity for pediatric outpatient care [42]. Use of the CSHCN Screener, a five-item scale that identifies needs, helps to target CSHCN who need coordination, access to specialized and community-based services, and enhanced SDM. However, lack of integration into EHR limits the use of the CSHCN Screener in many clinical settings $[43,44]$. A greater percentage of CMC may use social work services than non-CMC, with over eight times more hours of services provided per child per year [45]. Overall family-centered care planning and delivery for CMC is optimized when the medical and social needs of the child are integrated [46]. High performing community-based complex care clinics integrated with a tertiary care center may lead to a decrease in total health care system costs per patient per month, fewer inpatient days in the tertiary care center, decreased out of pocket expenses, and durable improvements in social and emotional quality of life for children [47]. Strategies to improve coordination have included scheduling additional time with patients and caregivers, summative care plans, and facilitated synchronous and asynchronous communication with specialists [9].

\section{Comprehensive Medication Management (CMM)}

The American College of Clinical Pharmacy (ACCP) recently developed a common language document for delivering CMM [48]. Vital to communicating both internally and external to the profession, and especially to patients, the document contains the operational definitions that assure a standardized patient care process within each essential pharmacist function, as outlined below:

1. Collect and analyze information about the patient and drug therapy history;

2. Assess the information and formulate a medication therapy problem (MTPs) list;

3. Develop the care plan in collaboration with healthcare team and patient/caregiver;

4. Implement the care plan; and

5. Follow up and monitor to optimize the care plan and resolve MTPs.

Applying implementation science principles into practice in a stepwise fashion, especially creating "bite-sized objectives" through SMART goals (Specific, Measurable, Actionable, Realistic, and Time-bound) and enlisting physician champions, has been shown to produce positive outcomes for integrating clinical pharmacists in adult primary care practices [49]. Clinical pharmacists practicing under collaborative practice agreements (CPAs) or through other privileging processes are well positioned to improve care coordination through provision of CMM. As shown in Figure 2, CMM is founded on three core components: (1) a shared philosophy of practice; (2) the patient care process; and (3) practice management systems.

In 2011, 90\% of all Medicaid-insured CMC required medications that averaged US $\$ 1677$ per child [50]. CMC represents about $3 \%$ of $C S H C N$, and CMC parents report significantly more unmet needs for prescription medications and care coordination compared to non-CMC parents. These may be associated with unmet care coordination and greater medical complexity. Pharmacists are rarely part of the CSHCN care coordination model. With the complexity of and numerous transitions of care 
for CSHCN-CMC, pharmacists can be responsible to advocate for the unfulfilled needs for prescription medications as care delivery models for these children evolve [12].

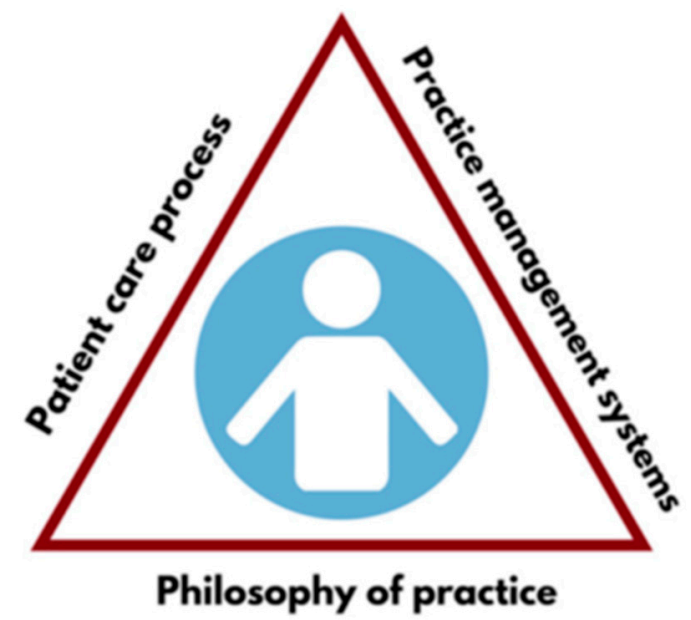

Figure 2. Comprehensive Medication Management framework [48].

The American College of Clinical Pharmacy (ACCP) believes that clinical pharmacists engaged in direct patient care activities such as CMM should be board certified (i.e., residency-trained or otherwise board eligible) and have established valid CPAs or have been formally granted clinical privileges [51-55].

CMM is a primary method for medication optimization, a result of merging implementation science expertise with lessons learned from the "CMM in Primary Care" grant $[48,53]$. Six essential domains common to other health disciplines comprise CMM: "direct patient care, pharmacotherapy knowledge, systems-based care and population health, communication, professionalism, and continuing professional development." These competencies are specifically designed to identify the unique clinical pharmacy expertise needed to provide CMM from a patient-centered, team-based perspective" [54,55]. Face-to-face CMM has resulted in increased rates of medication adherence [56]. Since 1995, the Department of Veterans Affairs has allowed Clinical Pharmacy Specialists (CPS) an expanded scope of practice with independent prescribing privileges [57].

Physicians have identified enhanced clinical outcomes, access to drug knowledge, and creation of a multidisciplinary model for learners as the top benefits of working with clinical pharmacists, but note limited reimbursement and billing difficulties as primary challenges [58]. Access to primary care health records can help community pharmacists build an efficient and effective CMM practice [59].

\section{Collaborative Practice and Agreements (CPA)}

In 2012, the American Pharmacists Association Foundation convened a roundtable consortium that generated seven recommendations for advancing pharmacists' patient care services and CPAs which included:

- "use of consistent terminology;

- provider control over collaborative practice details;

- infrastructure that embeds pharmacists' patient care services and CPAs into care;

- use of electronic health records and technology in patient care services;

- relationships among the health care team that are strong, trusting, and mutually beneficial;

- incentive alignments based on meaningful process and outcome measures; and

- redesign of health professionals' practice acts, education curriculums, and operational policies" (see Figure 3) [60,61]. 


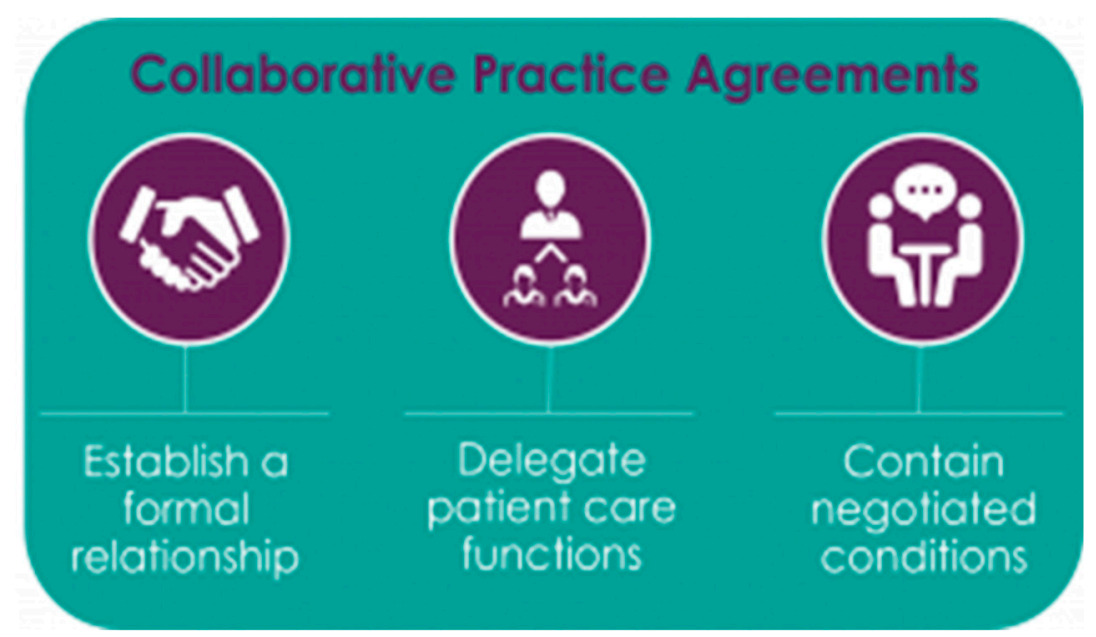

Figure 3. Collaborative Practice Agreement Process [60].

There are two primary categories of current pharmacist prescriptive authority: (1) collaborative prescribing; and (2) autonomous prescribing. Collaborative prescribing models provide a conceptual framework for treating diagnosis-established acute and/or chronic disease while autonomous prescribing models focus on a limited range of medications for minor ailments $[62,63]$. Practice law in four states have created advanced practice pharmacist designations, including: advanced practice (California), clinical pharmacist practitioner (Montana and North Carolina), and pharmacist clinician (New Mexico). These designations may not translate to actual scope of practice gains by comparison to other existing state laws [64,65].

To design effective community pharmacy-based point-of-care (POC) testing, development of trust between the physician and pharmacist is often based on reputation [66,67]. The most important pharmacist contributions in drug therapy that physicians have identified include adverse effect and drug interaction management, and medication access assistance education, and adherence [68]. Concise progress notes have been highlighted [69]. Examples of effective specific strategies for CPAs may include using existing physician relationships, identifying pharmacy- and regional-level champions, and allocating staffing based on prescription volume and clinical services [70]. As described for Texas federally qualified health centers, a PCMH co-visit model may induce more collaboration with physicians and more patient convenience; however, payment for the value of PCMH is not universal [71]. Physicians' perceived barriers for collaboration have been reported to be concern over loss of communication, hesitancy to relinquish control, and lack of confidence in pharmacists' clinical judgement [72]. Assurance of pharmacist preparedness and continuous professional development through profession-wide standards for prescribing processes will be imperative [73].

Clinical pharmacists and physicians have entered into CPAs in adult patients for at least 25 years using disease - or body system — based agreements as facilitated through state board of pharmacy and medicine collaborative practice statutes and regulations. These CPAs vary greatly from state to state; however, most regulations specify medication prescribing (initiating, modifying, and/or discontinuing pharmacotherapy), required laboratory monitoring (either venipuncture or POC), and other aspects of therapy (e.g., insurance authorizations). A CPA allows a qualified pharmacist to assess patients, order relevant laboratory tests, administer medications, and select, initiate, monitor, and adjust pharmacotherapy in collaboration with physicians and other prescribers. According to the Centers for Disease Control and Prevention, there is ample evidence that CMM enabled through a CPA effectively achieves intended outcomes [74].

CMM focuses on optimizing the patient's entire drug therapy whereas disease management is centered on one disease state, such as diabetes, heart failure, asthma, and hypertension. In the case of CPAs involving children, CMM could be initiated in patients with two or more active chronic diagnoses that are managed with medications [75,76], for immunizations [77], during transitions 
of care from hospital to home [12,78], or when children with neurodevelopmental issues become adolescents [79-82].

Many jurisdictions in North America allow for pharmacists and physicians to determine the extent to which a patient is involved in a CPA, including informed consent and written consent with opt-out provisions. It is important to specify in detail the expectations and responsibilities for care. If guidelines or practice parameters are available, it is suggested that these documents form the clinical basis of the CPA. Specific definitions of drug therapy management have included adjusting a drug regimen, adjusting drug strength, frequency or route of administration, administering drugs, ordering pertinent laboratory tests, monitoring vital signs, and educating and training patients related to home management of drug therapy. A toolkit for creating CPAs for CMM in other countries is described in another paper of this Special Issue.

\section{Network Design Requirements and Electronic Health Record (EHR) Needs}

\subsection{Overview}

The speed of change from volume-based to value-based payment in health care varies widely. Focusing on the family's well-being goals, successful community-based PH models have leveraged strong payer-provider partnerships have the potential to reduce healthcare costs and maintaining or improving care quality $[83,84]$. Figure 4 illustrates one $\mathrm{PH}$ structure where pharmacotherapy may be involved for CSHCN-CMC at several nodes in the care process. When considering the constitution of a pharmacy-based network, it is important to understand how pharmacotherapy assessment, monitoring, and follow up can be situated within the core capabilities of behavioral health, complex disease management, telehealth, and care management. Moreover, how well these core components articulate with adjacent capabilities, such as primary care networks and pediatric to adult transitions, can improve care coordination for overall medication management and positive patient outcomes.

Examples that utilize such PHM models can occur in various settings. Pharmacists have provided patient care using CPAs for diabetes, hypertension, and hyperlipidemia in PCMH clinics. Legal agreements were developed for sharing data and for accessing state-wide EHR at a large chain community pharmacy in one US state for over five years. No statistically significant differences were seen in blood glucose, lipids, or blood pressure outcomes for patients seen by PCMH versus community pharmacists, indicating that, when EHR is available, CMM can be conducted without regard to location [85]. A discharge clinic approach achieved a significant decrease in 30-day readmission rate compared with national benchmark data. The medical group's estimated cost of readmissions was US $\$ 7,156,800$, and 30 -day all-cause readmission rate was $12.3 \%$. Use of a post discharge clinic resulted in an estimated savings of $\$ 689,199$ and $9.63 \%$, a total estimated net savings of $\$ 335,199$ [86]. An ambulatory care pharmacy-based transitions-of-care (TOC) program for 830 managed Medicaid patients reduced total healthcare costs at 180 days after discharge by an average of $\$ 2139$ or an estimated plan savings of nearly $\$ 1.8$ million [87]. 


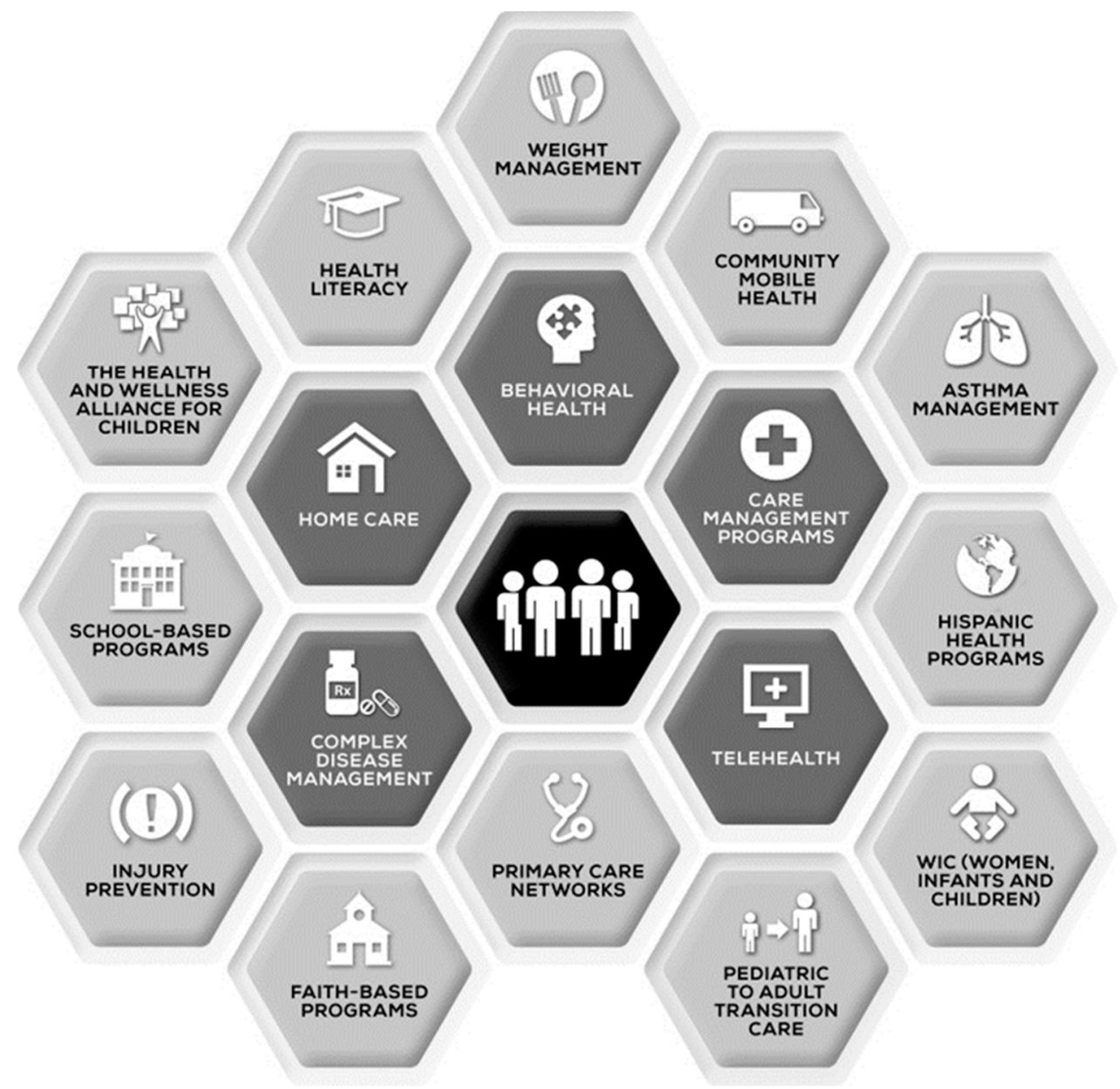

Figure 4. Population health (PH) capabilities [83].

\subsection{Potential Models and Accompanying Logistical Needs}

To provide for the overarching structure, potential network models are evolving. There are pharmacy-based, pediatrician office-based, telehealth (call center) based and hybrid, multi-level models. Within the pharmacy-based network, there are several existing clinically-integrated community focused networks wherein pediatric patients may receive CMM. An example of this structure is the National Association of Community Pharmacy-Community Pharmacy Enhanced Services Network (CPESN); within CPESN, all member pharmacies are capable of providing the following medication management services, including reconciliation, synchronization, vaccinations, and CMM. Additional services at select pharmacies include collection of vital signs, POC testing, administration of long-acting injections, and compounding sterile and non-sterile preparations. CPESN support solutions include quality improvement, quality assurance and practice transformation guided by CPESN clinicians and data analysts.

Some pharmacy supplier-based networks with internal clinical infrastructure can support collaborative practices (Professional Compounding Centers of America (PCCA; https://www.pccarx. com/); International Academy of Compounding Pharmacists (IACP; https://www.iacprx.org/); and Cardinal Health; https://www.outcomesmtm.com/pharmacy/medication-therapy-management/).

The infrastructure of these networks often is comprised of in-house clinical and scientific expertise that assists community pharmacists in collaboration with patients and pediatricians. For example, within Cardinal Health's OutcomesMTM ${ }^{\circledR}$ company, patients are connected through the Personal Pharmacist ${ }^{\mathrm{TM}}$ Network with face-to-face and telepharmacy components to leverage pharmacists with unique access to prescribers, some of which are embedded in physician practices. Alternatively, 
standards-setting organizations and professional societies that have the pharmacotherapy of children as their central focus might organize collaborative and electronic networks exclusively designed to improve drug therapy outcomes in pediatrics as a population. In other words, pharmacotherapy and medication management systems for children need to include more than federal governmental approvals and pediatric society efforts; the complexities in CSHCN require increased orchestrated transdisciplinary collaboration designed to foster innovation through practice-based research and innovation.

While the number of pharmacists practicing CMM within pediatrician offices is unknown, several health system-based clinics have formed collaborations internally and with large community chain pharmacy organizations and companies to facilitate collaborative care $[88,89]$. In these collaborations, ambulatory clinical pharmacists are included on inter-professional outpatient teams to optimize medication use. Outpatient pharmacists conducted medication reviews while ambulatory clinical pharmacists focused on CMM. Specialty groups, such as the Childhood Arthritis and Rheumatology Research Alliance in North America and others focused on outpatient chronic care management, afford another potential network arrangement for pharmacist-pediatrician collaboration [90,91]. In a pilot study, collaboration between a community pharmacy and local pediatric primary care centers targeted asthma, a major chronic disease in children [92].

CMM can be provided via telehealth applications [93]. Primary care outcomes in a telehealth-based chronic disease management program that includes clinical pharmacists for diabetes, hyperlipidemia, hypertension control and tobacco cessation can be achieved in targeted patients [94]. Multidisciplinary therapeutic class management in pediatric behavioral health completed peer-to-peer consultations via telepharmacy for medication changes, dose reductions, and elimination of polypharmacy within or across behavioral health medication classes [79].

\section{Consistent Documentation of CMM by Pharmacists in CSHCN-CMC Populations}

\subsection{Current Gaps in Pediatric Medication Management}

A joint opinion of the ACCP Pediatrics Practice and Research Network and the Pediatric Pharmacy Advocacy Group outlined four strategies to expand the quality and capacity of pediatric clinical pharmacist care, including elevating minimum entry-to-practice expectations, standardizing education, expanding the number of pediatric clinical pharmacists, and addressing research development of pediatric clinical pharmacists and clinical scientists. The ultimate goal was to improve access for all pediatric patients, including CSHCN [95]. In addition, there are many gaps in the current system for medication management that directly affect pediatric patients and their families. These gaps can be divided into four major areas of attention: (1) lack of standardized formulations designed for children; (2) lack of information exchange and standard nomenclature to describe products used in children; (3) lack of collaboration for CMM between pediatricians and clinical pharmacists at the point of care; and (4) lack of effective feedback for understanding the impact of pharmacotherapy on patient outcomes.

Mass-produced drug products and formulations suitable for children, especially those below the age of 6 years, are lacking. Useful active pharmaceutical ingredients (APIs) with finished oral liquid dosage forms available either adapted from other countries or registered in North America and beyond has been suggested [96,97]. To optimize the effectiveness and safety of "off-label" use of compounded pharmacotherapy through complete transmission of electronic prescriptions across the continuum of care, a pediatric compounded non-sterile products repository (pCNSP) has been proposed [98]. Existing federal and corporate database structures for medical language could be employed to incorporate pCNSPs to facilitate complete transmission of electronically identifiable and standardized extemporaneous formulations. The lack of inclusion also stymies a uniform approach to CMM for pediatric patients, as these products do not appear on the patients' medication records accurately [99]. 
Because medication use in children continues to be associated with an unacceptably high rate of adverse events, morbidity, and death, a distinct medicines-use system designed explicitly for them has been proposed [100]. A rise in the prevalence in chronic diseases such as diabetes, obesity, and inflammatory bowel diseases, is causing an increased utilization of medications that can lead to more medication errors or adverse drug events. For example, obesity now affects almost $20 \%$ of U.S. children and adolescents. Morbid obesity now affects 6\% of all U.S. youth [101]. CMM in this rapidly-rising sub-population should consider for potential for drug-induced weight gain where pharmacists are embedded in the inter-professional ambulatory or community healthcare delivery for pediatric patients. Pediatric polypharmacy can be addressed through CMM services, chart reviews, and other medication-related activities [102]. Pediatric pharmacy has recently been credentialed as a board-certified pharmacy specialty through the auspices of the Board of Pharmacy Specialties (https://www.bpsweb.org) [103]. Any new network that develops for the management of pharmacotherapy in children would be bolstered with the inclusion of board-certified pediatric pharmacy specialists (BCPPS) located within health system or pediatrician group practices or within internal support staffs of community, chain, and/or supplier organizations.

\subsection{Potential Network Architectures, Configuration, and Designs}

There are two essential components of any network designed to provide patient care or services: (1) human factors related to the proximity among providers of care delivery; and (2) informatics infrastructure related to health data gathering, storage, and routing/transmission. Any design must assure that the network is stable, secure, and sustainable over time. While there are many architectures, configurations, and designs that could be employed to network CMM in pediatric pharmacotherapy, it is important that these structures be designed intentionally with the end user, children and their families, in mind. In addition, there needs to be a simulation aspect to any network so that changes in system requirements, inputs, and outputs can be tested prior to activation in a production environment.

There are two common paradigms that facilitate the distribution of information: (1) hub and spoke architectures; and (2) multicasting architectures [104]. It has been shown that providers need to connect visually and on an interpersonal basis. Applied to pediatric providers involved in this network, their proximity to each other, whether face-to-face, within the same local community, or remote / distance, is an important factor in trust development and network sustainment.

Hub and spoke designs have been applied to health care systems involving providers and informatics, academic settings, and research endeavors (see Figure 5). These involve a central unit (hub or message broker) that receives transmissions from an initiator and distributes messages to listener objects. In this structure, there may be one hub object per channel or a single master object to connect with all channels, facilitate data sharing, and SDM. In this design, the transmitter (care initiator) sends data (clinical observations and documentation, including $\mathrm{eRx}$ ) to the network hub. The hub is comprised of listener objects (authorized care manager devices) assigned to receive information from the transmitter. The listener interprets the message and sends a new message to a terminal recipient. 


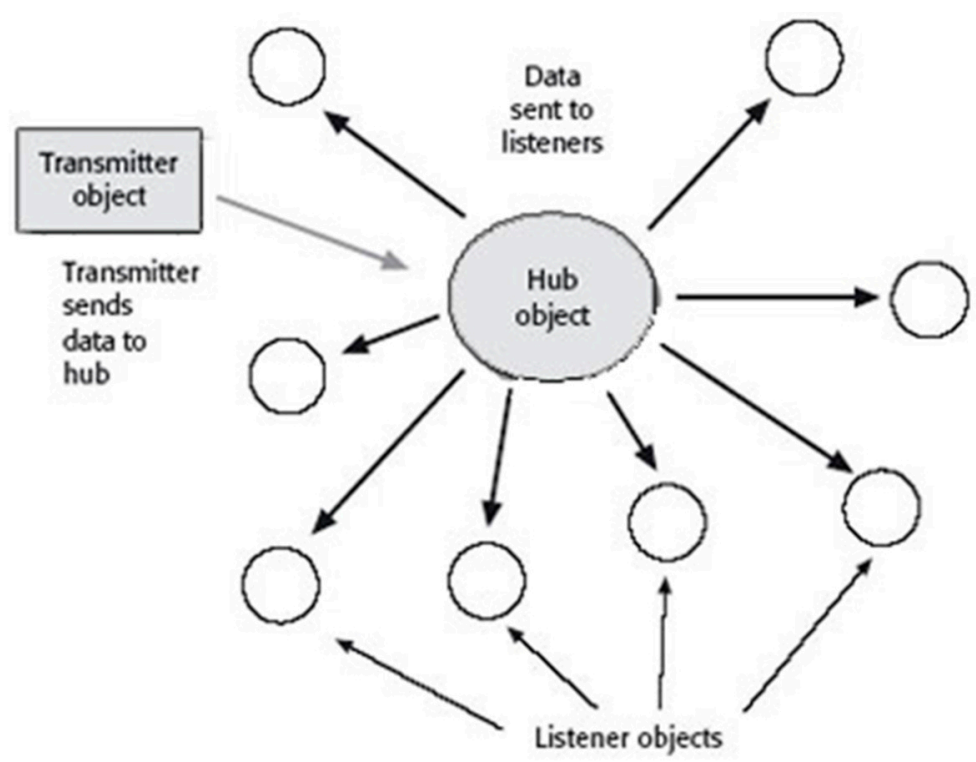

Figure 5. Hub and spoke architecture [104].

Multicast involves passing synchronous messages within one or more channels that signal end users when information is available in the channel (see Figure 6). Copies are created and routed automatically to network segments that contain members of the listener object group.

In either case, network architectures for both practitioners and data can be situated in tandem or separately. For example, the Surescripts Network Alliance ${ }^{\mathrm{TM}}$ began as a functionality to facilitate electronic prescribing, and has evolved a repository for medication histories and prior authorization functionality [105]. Surescripts connects payers and pharmacy benefit managers, pharmacies, inpatient and outpatient prescribing and dispensing software, and hospitals and care providers [106]. A similar platform can be derived for a separate and distinct prescription-processing and medication management system that provides access to authorized practitioners caring for the needs of children and their families.

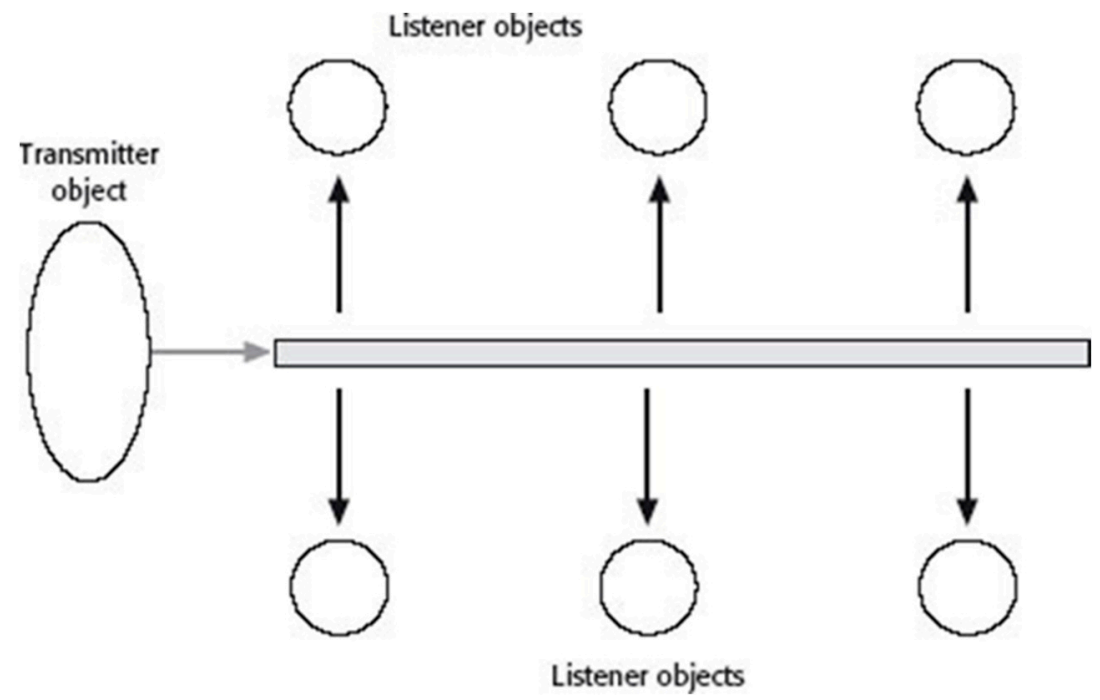

Figure 6. Multicast architecture [104].

\subsection{Estimating the Number of Clinical Pharmacists Needed to Care for CSHCN-CMC}

Although population estimates of the number of pharmacists needed in society is based on prescription fulfillment, data from the Bureau of Labor Statistics have shown repeatedly that there are 
about one-third as many pharmacists as physicians; in 2016, there were 713,800 physicians and surgeons practicing in the US [107]. According to the American Academy of Pediatrics (AAP), there were about 92,000 physician-pediatricians and over 28,000 medical and surgical sub-specialists, or about 120,000 pediatricians [108]. The AAP also believes that there is a current shortage of sub-specialty-trained pediatricians, and the distribution of generalists and primary care in rural and other underserved areas is inadequate [19]. Since estimates of CSHCN and sub-groups is elusive presently, a reasonable projection of the direct care needs of CSHCN-CMC for clinical pharmacists providing CMM in the U.S. ranges from a 1:3 to a 1:5 ratio to pediatricians, including sub-specialists. In the U.S., this would translate conservatively into between 24,000 and 40,000 clinical pharmacists needed, bearing in mind that the ratio for patients with complex chronic needs may be lower than for primary care, unless primary care is the PCMH. Moreover, the number of clinical pharmacists needed is affected by the extent to which sterile and non-sterile compounding and prescription fulfillment activities are part of the practice in addition to CMM. However, it is apparent from the preceding discussion that clinical pharmacists practicing CMM for CSHCN can improve access to safe and effective pharmacotherapies. The professions need to collaborate at local and national levels as a way of practicing in order to achieve measurable outcomes.

\section{Summary and Recommendations}

This report contains forward-thinking statements designed to stimulate mindfulness and concerted action for improving healthcare delivery and medication management in children. Medication use is a major aspect of CSHCN, and mismanagement is fraught with ambiguity, error, and morbidity. Including board-certified pediatric clinical pharmacists providing CMM, either on-site (such as in a PCMH) or remotely, in evolving population health care networks for children has been proposed in an effort to create a dialogue that improves the likelihood for individual and population health optimization. As a medication optimization strategy, $\mathrm{CMM}$ has a common language and terminology for operationally defining direct patient care rendered by clinical pharmacists. Learnings from CMM application in adult primary care may afford better understanding of the potential for pharmacist collaborative care across the pediatric continuum.

The evolution of a network of clinical pharmacists providing CMM for CSHCN may be best facilitated by insertion of pediatrics-trained and board-certified faculty from schools and colleges of pharmacy into ambulatory clinics of pediatric hospitals and health systems. Alternatively, existing pharmacist provider networks, such as the Community Pharmacy Enhanced Network and the Personal Pharmacist Network, may expand to include CMM for children based on a set of shared collaborative practice objectives. These two approaches may be integrated to form a regional network that improves access both to board-certified pediatric pharmacy specialists and to quality medications. CPAs involving children's CMM could be initiated in patients with two or more active chronic diagnoses that are managed with medications, for immunizations, or during transitions of care from hospital to home.

Author Contributions: conceptualization, R.H.P.II and J.v.d.A.; writing-original draft preparation, R.H.P.II; writing一review and editing, R.H.P.II, D.C., J.v.d.A., S.B.; project administration, R.H.P.II.

Funding: This research received no external funding.

Conflicts of Interest: The authors declare no conflict of interest. 


\section{Abbreviations}

$\begin{array}{ll}\text { AAP } & \text { American Academy of Pediatricians } \\ \text { ACCP } & \text { American College of Clinical Pharmacy } \\ \text { APhA } & \text { American Pharmacists Association } \\ \text { BCPPS } & \text { Board-certified pediatric pharmacy specialists } \\ \text { CMC } & \text { children with medical complexity } \\ \text { CMM } & \text { comprehensive medication management } \\ \text { CPA } & \text { collaborative practice agreement } \\ \text { CSHCN } & \text { children with special health care needs } \\ \text { EHR } & \text { electronic health record } \\ \text { PCMH } & \text { patient centered medical home } \\ \text { PCP } & \text { community primary care provider } \\ \text { pCNSP } & \text { pediatric compounded nonsterile preparation } \\ \text { PH } & \text { population health } \\ \text { PHM } & \text { population health management } \\ \text { SDM } & \text { shared decision making } \\ \text { TOC } & \text { transitions of care } \\ \text { YSHCN } & \text { youth with special health care needs }\end{array}$

\section{References}

1. Skinner, D.; Franz, B.; Taylor, M.; Shaw, C.; Kelleher, K.J. How U.S. children's hospitals define population health: A qualitative, interview-based study. BMC Health Serv. Res. 2018, 18, 494. [CrossRef] [PubMed]

2. Health Resources and Services Administration; Maternal and Child Health Bureau. Children with Special Health Care Needs. Available online: https://mchb.hrsa.gov/maternal-child-health-topics/children-andyouth-special-health-needs\#ref1 (accessed on 4 February 2019).

3. Children's Hospital Association. Defining Children with Medical Complexities. Available online: https://www.childrenshospitals.org/issues-and-advocacy/children-with-medical-complexity/factsheets/defining-children-with-medical-complexities (accessed on 4 February 2019).

4. Cohen, E.; Berry, J.; Sanders, L.; Schor, E.L.; Wise, P.H. Status complexicus? The emergence of pediatric complex care. Pediatrics 2018, 141 (Suppl. 3), S202-S211. [CrossRef]

5. Breneol, S.; Belliveau, J.; Cassidy, C.; Curran, J.A. Strategies to support transitions from hospital to home for children with medical complexity: A scoping review. Int. J. Nurs. Stud. 2017, 72, 91-104. [CrossRef]

6. Pordes, E.; Gordon, J.; Sanders, L.M.; Cohen, E. Models of care delivery for children with medical complexity. Pediatrics 2018, 141 (Suppl. 3), S212-S223. [CrossRef] [PubMed]

7. Agrawal, R. Complex care in pediatrics: Great progress, greater challenges. J. Pediatr. Rehabil. Med. 2015, 8, 71-74. [CrossRef] [PubMed]

8. $\quad$ Barnert, E.S.; Coller, R.J.; Nelson, B.B.; Thompson, L.R.; Chan, V.; Padilla, C.; Klitzner, T.S.; Szilagyi, M.; Chung, P.J. Experts' perspectives toward a population health approach for children with medical complexity. Acad. Pediatr. 2017, 17, 672-677. [CrossRef] [PubMed]

9. Foster, C.C.; Mangione-Smith, R.; Simon, T.D. Caring for children with medical complexity: Perspectives of primary care providers. J. Pediatr. 2017, 182, 275-282.e4. [CrossRef]

10. Parasuraman, S.R.; Anglin, T.M.; McLellan, S.E.; Riley, C.; Mann, M.Y. Health care utilization and unmet need among youth with special health care needs. J. Adolesc. Health 2018, 63, 435-444. [CrossRef] [PubMed]

11. Kenney, M.K.; Thierry, J. Chronic conditions, functional difficulties, and disease burden among American Indian/Alaska Native children with special health care needs, 2009-2010. Matern. Child Health J. 2014, 18, 2071-2079. [CrossRef]

12. Aboneh, E.A.; Chui, M.A. Care coordination, medical complexity, and unmet need for prescription medications among children with special health care needs. Res. Soc. Adm. Pharm. 2017, 13, 524-529. [CrossRef]

13. Patient-Centered Primary Care Collaborative. The Patient-Centered Medical Home: Integrating Comprehensive Medication Management to Optimize Patient Outcomes. Available online: https: //www.pcpcc.org/sites/default/files/media/medmanagement.pdf (accessed on 3 January 2019). 
14. Kuo, D.Z.; Melguizo-Castro, M.; Goudie, A.; Nick, T.G.; Robbins, J.M.; Casey, P.H. Variation in child health care utilization by medical complexity. Matern. Child Health J. 2015, 19, 40-48. [CrossRef] [PubMed]

15. Galligan, M.M.; Bamat, T.W.; Hogan, A.K.; Piccione, J. The pediatric aerodigestive center as a tertiary care-based medical home: A proposed model. Curr. Probl. Pediatr. Adolesc. Health Care 2018, 48, 104-110. [CrossRef] [PubMed]

16. Nygård, C.; Clancy, A. Unsung heroes, flying blind-A metasynthesis of parents' experiences of caring for children with special health-care needs at home. J. Clin. Nurs. 2018, 27, 3179-3196. [CrossRef] [PubMed]

17. Kuo, D.Z.; Robbins, J.M.; Lyle, R.E.; Barrett, K.W.; Burns, K.H.; Casey, P.H. Parent-reported outcomes of comprehensive care for children with medical complexity. Fam. Syst. Health 2013, 31, 132-141. [CrossRef]

18. Kindig, D.A. Improving Population Health-Policy, Practice, Research. Available online: https://www. improvingpopulationhealth.org/blog/what-is-population-health.html (accessed on 3 January 2019).

19. American Academy of Pediatrics; Committee on Pediatric Workforce. Pediatrician Workforce Policy Statement. Pediatrics 2013, 132, 390. [CrossRef] [PubMed]

20. U.S. Department of Health and Human Services; Agency for Health Research and Quality. Patient Centered Medical Home Resource Center. Defining the PCMH. Available online: https://pcmh.ahrq.gov/page/definingpcmh (accessed on 3 January 2019).

21. Foreman, J.; Harrod, M.; Robinson, C.; Annis-Emeott, A.; Ott, J.; Saffar, D.; Krein, S.; Greenston, C.L. First things first: Foundational requirements for a medical home in an academic medical center. J. Gen. Intern. Med. 2014, 29 (Suppl. 2), 640-648. [CrossRef]

22. Lipson, D.; Rich, E.; Libersky, J.; Parchman, M. Ensuring That Patient-Centered Medical Homes Effectively Serve Patients with Complex Health Needs; (Prepared by Mathematica Policy Research under Contract No. HHSA290200900019I TO 2.) AHRQ Publication No. 11-0109; Agency for Healthcare Research and Quality: Rockville, MD, USA, 2011.

23. Lichstein, J.C.; Ghandour, R.M.; Mann, M.Y. Access to the medical home among children with and without special health care needs. Pediatrics 2018, 142, e20181795. [CrossRef] [PubMed]

24. Coller, R.J.; Lerner, C.F.; Eickhoff, J.C.; Klitzner, T.S.; Sklansky, D.J.; Ehlenbach, M.; Chung, P.J. Medical complexity among children with special health care needs: A Two-dimensional view. Health Serv. Res. 2016, 51, 1644-1669. [CrossRef]

25. Bramlett, M.D.; Read, D.; Bethell, C.; Blumberg, S.J. Differentiating subgroups of children with special health care needs by health status and complexity of health care needs. Matern. Child Health J. 2009, 13, 151-163. [CrossRef]

26. Rosen-Reynoso, M.; Porche, M.V.; Kwan, N.; Bethell, C.; Thomas, V.; Robertson, J.; Hawes, E.; Foley, S.; Palfrey, J. Disparities in access to easy-to-use services for children with special health care needs. Matern. Child Health J. 2016, 20, 1041-1053. [CrossRef]

27. Lin, J.L.; Cohen, E.; Sanders, L.M. Shared decision making among children with medical complexity: Results from a population-based survey. J. Pediatr. 2018, 192, 216-222. [CrossRef] [PubMed]

28. Kuo, D.Z.; Goudie, A.; Cohen, E.; Houtrow, A.; Agrawal, R.; Carle, A.C.; Wells, N. Inequities in health care needs for children with medical complexity. Health Aff. (Millwood) 2014, 33, 2190-2198. [CrossRef] [PubMed]

29. Okumura, M.J.; Knauer, H.A.; Calvin, K.E.; Takayama, J.I. Pediatricians' comfort level in caring for children with special health care needs. Acad. Pediatr. 2017, 17, 678-686. [CrossRef] [PubMed]

30. Van Cleave, J.; Okumura, M.J.; Swigonski, N.; O'Connor, K.G.; Mann, M.; Lail, J.L. Medical homes for children with special health care needs: Primary care or subspecialty service? Acad. Pediatr. 2016, 16, 366-372. [CrossRef] [PubMed]

31. Agrawal, R.; Smith, T.; Li, Y.; Cartland, J. Rate of spending on chronic conditions among Medicaid and CHIP recipients. Pediatrics 2014, 134, e80-e87. [CrossRef] [PubMed]

32. Tuomela, K.E.; Gordon, J.B.; Cassidy, L.D.; Johaningsmeir, S.; Ghanayem, N.S. Resource utilization associated with extracardiac co-morbid conditions following congenital heart surgery in infancy. Pediatr. Cardiol. 2017, 38, 1065-1070. [CrossRef] [PubMed]

33. McKenzie, R.B.; Sanders, L.; Bhattacharya, J.; Bundorf, M.K. Health care system factors associated with transition preparation in youth with special health care needs. Popul. Health Manag. 2019, 22, 63-73. [CrossRef] [PubMed] 
34. Hergenroeder, A.C.; Wiemann, C.M.; Bowman, V.F. Lessons learned in building a hospital-wide transition program from pediatric to adult-based health care for youth with special health care needs (YSHCN). Int. J. Adolesc. Med. Health 2016, 28, 455-458. [CrossRef]

35. Bridgemohan, C.; Bauer, N.S.; Nielsen, B.A.; DeBattista, A.; Ruch-Ross, H.S.; Paul, L.B.; Roizen, N. A workforce survey on developmental-behavioral pediatrics. Pediatrics 2018, 141, e20172164. [CrossRef] [PubMed]

36. An, R. Unmet mental health care needs in U.S. children with medical complexity, 2005-2010. J. Psychosom. Res. 2016, 82, 1-3. [CrossRef]

37. Wyatt, K.D.; List, B.; Brinkman, W.B.; Prutsky Lopez, G.; Asi, N.; Erwin, P.; Wang, Z.; Domecq Garces, J.P.; Montori, V.M.; LeBlanc, A. Shared decision making in pediatrics: A systematic review and meta-analysis. Acad. Pediatr. 2015, 15, 573-583. [CrossRef] [PubMed]

38. Lipstein, E.A.; Lindly, O.J.; Anixt, J.S.; Britto, M.T.; Zuckerman, K.E. Shared decision making in the care of children with developmental and behavioral disorders. Matern. Child Health J. 2016, 20, 665-673. [CrossRef] [PubMed]

39. McDonald, K.M.; Schultz, E.; Pineda, N.; Lonhart, J.; Chapman, T.; Davies, S. Care Coordination Accountability Measures for Primary Care Practice; AHRQ Publication No. 12-0019-EF; Agency for Healthcare Research and Quality: Rockville, MD, USA, 2012.

40. Arthur, K.C.; Mangione-Smith, R.; Burkhart, Q.; Parast, L.; Liu, H.; Elliott, M.N.; McGlynn, E.A.; Schneider, E.C. Quality of care for children with medical complexity: An analysis of continuity of care as a potential quality indicator. Acad. Pediatr. 2018, 18, 669-676. [CrossRef]

41. Parast, L.; Burkhart, Q.; Gidengil, C.; Schneider, E.C.; Mangione-Smith, R.; Lion, C.; McGlynn, E.A.; Carle, A.; Britto, M.T.; Elliott, M.N. Validation of new care coordination quality measures for children with medical complexity. Acta Pediatr. 2018, 18, 581-588. [CrossRef]

42. O'Brien, J.E.; Dumas, H.M. Development and initial psychometric evaluation of the Post-Acute Acuity Rating for Children. Rehabil. Res. Pract. 2015, 2015, 841523. [CrossRef] [PubMed]

43. Bethell, C.D.; Blumberg, S.J.; Stein, R.E.; Strickland, B.; Robertson, J.; Newacheck, P.W. Taking stock of the CSHCN screener: A review of common questions and current reflections. Acad. Pediatr. 2015, 15, 165-176. [CrossRef] [PubMed]

44. Davis, A.M.; McFadden, S.E.; Patterson, B.L.; Barkin, S.L. Strategies to identify and stratify children with special health care needs in outpatient general pediatrics settings. Matern. Child Health J. 2015, 19, 1384-1392. [CrossRef]

45. Coquillette, M.; Cox, J.E.; Cheek, S.; Webster, R.A. Social work services utilization by children with medical complexity. Matern. Child Health J. 2015, 19, 2707-2713. [CrossRef]

46. Adams, S.; Cohen, E.; Mahant, S.; Friedman, J.N.; Macculloch, R.; Nicholas, D.B. Exploring the usefulness of comprehensive care plans for children with medical complexity (CMC): A qualitative study. BMC Pediatr. 2013, 13, 10. [CrossRef]

47. Cohen, E.; Lacombe-Duncan, A.; Spalding, K.; MacInnis, J.; Nicholas, D.; Narayanan, U.G.; Gordon, M.; Margolis, I.; Friedman, J.N. Integrated complex care coordination for children with medical complexity: A mixed-methods evaluation of tertiary care-community collaboration. BMC Health Serv. Res. 2012, 12, 366. [CrossRef]

48. The Patient Care Process for Delivering Comprehensive Medication Management (CMM): Optimizing Medication Use in Patient-Centered, Team-Based Care Settings. CMM in Primary Care Research Team. July 2018. Available online: http://www.accp.com/cmm_care_process (accessed on 14 January 2019).

49. Blanchard, C.; Livet, M.; Ward, C.; Sorge, L.; Sorensen, T.D.; McClurg, M.R. The active implementation frameworks: A roadmap for advancing implementation of comprehensive medication management in primary care. Res. Soc. Adm. Pharm. 2017, 13, 922-929. [CrossRef] [PubMed]

50. Berry, J.G.; Hall, M.; Neff, J.; Goodman, D.; Cohen, E.; Agrawal, R.; Kuo, D.; Feudtner, C. Children with medical complexity and Medicaid: Spending and cost savings. Health Aff. (Proj. Hope) 2014, 33, 2199-2206. [CrossRef]

51. American College of Clinical Pharmacy; McBane, S.E.; Dopp, A.L.; Abe, A.; Benavides, S.; Chester, E.A.; Dixon, D.L.; Dunn, M.; Johnson, M.D.; Nigro, S.J.; et al. Collaborative drug therapy management and comprehensive medication management-2015. Pharmacotherapy 2015, 35, e39-e50. [PubMed] 
52. American College of Clinical Pharmacy Board of Regents; Maddux, M.S. Board of Regents commentary. Qualifications of pharmacists who provide direct patient care: Perspectives on the need for residency training and board certification. Pharmacotherapy 2013, 33, 888-891. [PubMed]

53. Livet, M.; Blanchard, C.; Sorensen, T.D.; McClung, M.R. An implementation system for medication optimization: Operationalizing comprehensive medication management delivery in primary care. J. Am. Coll. Clin. Pharm. 2018, 1, 14-20. [CrossRef]

54. Saseen, J.J.; Ripley, T.L.; Bondi, D.; Burke, J.M.; Cohen, L.J.; McBane, S.; McConnell, K.J.; Sackey, B.; Sanoski, C.; Simonyan, A.; et al. ACCP clinical pharmacist competencies. Pharmacotherapy 2017, 37, 630-636. [CrossRef]

55. Pestka, D.L.; Sorge, L.A.; McClurg, M.R.; Sorensen, T.D. The philosophy of practice for comprehensive medication management: Evaluating its meaning and application by practitioners. Pharmacotherapy 2018, 38, 69-79. [CrossRef] [PubMed]

56. Brummel, A.; Carlson, A.M. Comprehensive medication management and medication adherence for chronic conditions. J. Manag. Care Spec. Pharm. 2016, 22, 56-62. [CrossRef] [PubMed]

57. Greer, N.; Bolduc, J.; Geurkink, E.; Koeller, E.; Rector, T.; Olson, K.; MacDonald, R.; Wilt, T.J. Pharmacist-Led Chronic Disease Management: A Systematic Review of Effectiveness and Harms Compared to Usual Care [Internet]; VA Evidence-based Synthesis Program Reports; Department of Veterans Affairs (US): Washington, DC, USA, 2015.

58. Williams, C.R.; Woodall, T.; Wilson, C.G.; Griffin, R.; Galvin, S.L.; LaVallee, L.A.; Roberts, C.; Ives, T.J. Physician perceptions of integrating advanced practice pharmacists into practice. J. Am. Pharm. Assoc. (2003) 2018, 58, 73-78.e2. [CrossRef] [PubMed]

59. Van Lint, J.A.; Sorge, L.A.; Sorensen, T.D. Access to patients' health records for drug therapy problem determination by pharmacists. J. Am. Pharm. Assoc. (2003) 2015, 55, 278-281. [CrossRef]

60. National Alliance of State Pharmacy Associations. Collaborative Practice Agreements: Resources and More. Available online: https://naspa.us/resource/cpa/ (accessed on 2 January 2019).

61. American Pharmacists Association Foundation and American Pharmacists Association. Consortium Recommendations for Advancing Pharmacists' Patient Care Services and Collaborative Practice Agreements. J. Am. Pharm. Assoc. (2003) 2013, 53, e132-e141. [CrossRef]

62. Burns, A.L. Emerging developments in pharmacists' scope of practice to address unmet health care needs. Ann. Pharmacother. 2016, 50, 785-787. [CrossRef]

63. Adams, A.J.; Weaver, K.K. The continuum of pharmacist prescriptive authority. Ann. Pharmacother. 2016, 50, 778-784. [CrossRef]

64. Frost, T.P.; Adams, A.J. Are advanced practice pharmacist designations really advanced? Res. Soc. Adm. Pharm. 2018, 14, 501-504. [CrossRef] [PubMed]

65. Murawski, M.; Villa, K.R.; Dole, E.J.; Ives, T.J.; Tinker, D.; Colucci, V.J.; Perdiew, J. Advanced-practice pharmacists: Practice characteristics and reimbursement of pharmacists certified for collaborative clinical practice in New Mexico and North Carolina. Am. J. Health Syst. Pharm. 2011, 68, 2341-2350. [CrossRef] [PubMed]

66. Bacci, J.L.; Klepser, D.; Tilley, H.; Smith, J.K.; Klepser, M.E. Community pharmacy-based point-of-care testing: A case study of pharmacist-physician collaborative working relationships. Res. Soc. Adm. Pharm. 2018, 14, 112-115. [CrossRef]

67. Pezzino, N.C.; Marciniak, M.W.; Smith, M.G.; Ferreri, S.P. Physician-reported factors that encourage collaboration with community pharmacists. J. Am. Pharm. Assoc. (2003) 2017, 57, S279-S283.e2. [CrossRef] [PubMed]

68. Zillich, A.J.; McDonough, R.P.; Carter, B.L.; Doucette, W.R. Influential characteristics of physician/pharmacist collaborative relationships. Ann. Pharmacother. 2004, 38, 764-770. [CrossRef]

69. Shah, M.; Markel Vaysman, A.; Wilken, L. Medication therapy management clinic: Perception of healthcare professionals in a University medical center setting. Pharm. Pract. (Granada) 2013, 11, 173-177. [CrossRef]

70. Bacci, J.L.; Coley, K.C.; McGrath, K.K.; Abraham, O.; Adams, A.J.; McGivney, M.S. Strategies to facilitate the implementation of CPAs in chain community pharmacies. J. Am. Pharm. Assoc. (2003) 2016, 56, 257-265.e2. [CrossRef] [PubMed]

71. Wong, S.L.; Barner, J.C.; Sucic, K.; Nguyen, M.; Rascati, K.L. Integration of pharmacists into patient-centered medical homes in federally qualified health centers in Texas. J. Am. Pharm. Assoc. (2003) 2017, 57, 375-381. [CrossRef] [PubMed] 
72. Gordon, C.; Unni, E.; Montuoro, J.; Ogborn, D.B. Community pharmacist-led clinical services: physician's understanding, perceptions and readiness to collaborate in a Midwestern state in the United States. Int. J. Pharm. Pract. 2018, 26, 407-413. [CrossRef]

73. Zimmerman, K.M.; Salgado, T.M.; Goode, J.R.; Sisson, E.M.; Dixon, D.L. A prescription for prescribing: Ensuring continued pharmacist preparedness. Ann. Pharmacother. 2018, 52, 697-699. [CrossRef] [PubMed]

74. Centers for Disease Control and Prevention; Division for Heart Disease and Stroke Prevention. Pharmacy: Collaborative Practice Agreements to Enable Collaborative Drug Therapy Management. Available online: https://www.cdc.gov/dhdsp/pubs/guides/best-practices/pharmacist-cdtm.htm (accessed on 3 January 2019).

75. Vallejos, X.; Benavides, S. The Patient Protection and Affordable Care Act: Implications for pediatric pharmacy practice. Ann. Pharmacother. 2013, 47, 1075-1078. [CrossRef]

76. Benavides, S.; Madzhidova, S.; Hernandez, A.; Le, T.; Palma, S.M.; Stephen, S. Establishment of pediatric Medication Therapy Management: A proposed model. Pharmacy 2016, 4, 5. [CrossRef]

77. American Pharmacists Association. Pharmacist-Administered Immunizations: What Does Your State Allow? 2015. Available online: https://www.pharmacist.com/article/pharmacist-administered-immunizations-whatdoes-your-state-allow (accessed on 14 January 2019).

78. Budlong, H.; Brummel, A.; Rhodes, A.; Nici, H. Impact of comprehensive medication management on hospital readmission rates. Popul. Health Manag. 2018, 21, 395-400. [CrossRef] [PubMed]

79. Chiara, A.N.; Kashalikar, N.; Pomfret, T.C.; Lenz, K.; Faber, D.; Goldstein, J.; Clements, K.M.; Angelini, M.C.; Leto, P.; Jeffrey, P.L. An evaluation of a multidisciplinary pediatric behavioral health medication initiative workgroup's interventions on medication prescribing in a population of Medicaid patients. J. Manag. Care Spec. Pharm. 2018, 24, 746-751. [CrossRef]

80. Tallian, K.B.; Hirsch, J.D.; Kuo, G.M.; Chang, C.A.; Gilmer, T.; Messinger, M.; Chan, P.; Daniels, C.E.; Lee, K.C. Development of a pharmacist-psychiatrist collaborative medication therapy management clinic. J. Am. Pharm. Assoc. (2003) 2012, 52, e252-e258. [CrossRef]

81. Cobb, C.D. Optimizing medication use with a pharmacist-provided comprehensive medication management service for patients with psychiatric disorders. Pharmacotherapy 2014, 34, 1336-1340. [CrossRef] [PubMed]

82. Schneiderhan, M.E.; Shuster, S.M.; Davey, C.S. Twelve-month prospective randomized study of pharmacists utilizing point-of-care testing for metabolic syndrome and related conditions in subjects prescribed antipsychotics. Prim. Care Companion CNS Disord. 2014, 16. [CrossRef]

83. Durovich, C.J.; Roberts, P.W. Designing a community-based population health model. Popul. Health Manag. 2018, 21, 13-19. [CrossRef]

84. Peele, P.; Keyser, D.; Lovelace, J.; Moss, D. Advancing value-based population health management through payer-provider partnerships: Improving outcomes for children with complex conditions. J. Healthc. Qual. 2018, 40, e26-e32. [CrossRef] [PubMed]

85. Farris, K.; Mitrzyk, B.M.; Batra, P.; Peters, J.; Diez, H.L.; Yoo, A.; McKay, K.; Friend, K.; Danko, L.; Waber, R.; et al. Linking the patient-centered medical home to community pharmacy via an innovative pharmacist care model. J. Am. Pharm. Assoc. (2003) 2019, 59, 70-78.e3. [CrossRef] [PubMed]

86. Baldwin, S.M.; Zook, S.; Sanford, J. Implementing posthospital interprofessional care team visits to improve care transitions and decrease hospital readmission rates. Prof. Case Manag. 2018, 23, 264-271. [CrossRef] [PubMed]

87. Ni, W.; Colayco, D.; Hashimoto, J.; Komoto, K.; Gowda, C.; Wearda, B.; McCombs, J. Reduction of healthcare costs through a transitions-of-care program. Am. J. Health Syst. Pharm. 2018, 75, 613-621. [CrossRef] [PubMed]

88. Sneed, G.; Kappeler, K.; Gilmore, T.; Kuhn, C. Implementation of a medication therapy management collaborative within a pediatric health system. J. Am. Pharm. Assoc. (2003) 2018, 58, S114-S119. [CrossRef]

89. Matzke, G.R.; Moczygemba, L.R.; Williams, K.J.; Czar, M.J.; Lee, W.T. Impact of a pharmacist-physician collaborative care model on patient outcomes and health services utilization. Am. J. Health Syst. Pharm. 2018, 75, 1039-1047. [CrossRef] [PubMed]

90. Spencer, C.H.; Rouster-Stevens, K.; Gewanter, H.; Syverson, G.; Modica, R.; Schmidt, K.; Emery, H.; Wallace, C.; Grevich, S.; Nanda, K.; et al. Biologic therapies for refractory juvenile dermatomyositis: Five years of experience of the Childhood Arthritis and Rheumatology Research Alliance in North America. Pediatr. Rheumatol. Online J. 2017, 15, 50. [CrossRef] [PubMed] 
91. Brinkman, W.B.; Lipstein, E.A.; Taylor, J.; Schoettker, P.J.; Naylor, K.; Jones, K.; Vora, S.S.; Mims, C.C.; Roth-Wojcicki, E.; Gottlieb, B.; et al. Design and implementation of a decision aid for juvenile idiopathic arthritis medication choices. Pediatr. Rheumatol. Online J. 2017, 15, 48. [CrossRef]

92. Bradley, C.L.; Luder, H.R.; Beck, A.F.; Bowen, R.; Heaton, P.C.; Kahn, R.S.; Mansour, M.; Obszarski, S.; Frede, S.M. Pediatric asthma medication therapy management through community pharmacy and primary care collaboration. J. Am. Pharm. Assoc. (2003) 2016, 56, 455-460. [CrossRef]

93. Badowski, M.E.; Walker, S.; Bacchus, S.; Bartlett, S.; Chan, J.; Cochran, K.A.; Coon, S.; Liedtke, M.; Phillips, B.G.; White, T. Providing comprehensive medication management in telehealth. Pharmacotherapy 2018, 38, e7-e16. [CrossRef] [PubMed]

94. Litke, J.; Spoutz, L.; Ahlstrom, D.; Perdew, C.; Llamas, W.; Erickson, K. Impact of the clinical pharmacy specialist in telehealth primary care. Am. J. Health Syst. Pharm. 2018, 75, 982-986. [CrossRef]

95. Bhatt-Mehta, V.; Buck, M.L.; Chung, A.M.; Farrington, E.A.; Hagemann, T.M.; Hoff, D.S.; LaRochelle, J.M.; Pettit, R.S.; Phan, H.; Potts, A.L.; et al. Recommendations for meeting the pediatric patient's need for a clinical pharmacist: A joint opinion of the Pediatrics Practice and Research Network of the American College of Clinical Pharmacy and the Pediatric Pharmacy Advocacy Group. Pharmacotherapy 2013, 33, $243-251$. [CrossRef] [PubMed]

96. Bhatt-Mehta, V.; MacArthur, R.B.; Löbenberg, R.; Cies, J.J.; Cernak, I.; Parrish, R.H., 2nd. Development of an algorithm to identify mass production candidate molecules to develop children's oral medicines: A North American perspective. AAPS Open 2016, 2, 8. [CrossRef]

97. Parrish, R.H., 2nd. Current trends and emerging priorities in compounded preparations for children. Int. J. Pharm. Compd. 2018, 22, 358-366. [PubMed]

98. Parrish, R.H., 2nd; Benavides, S.; Malak, J.T.; Potts, A.L.; Guirguis, M.; Hagemann, T. Optimizing effectiveness in electronic prescriptions for pediatric outpatients: A call for responsive action. Pharmacy 2014, 2, 260-269.

99. Parrish, R.H., 2nd. Positioning a paediatric compounded non-sterile product electronic repository (pCNPeRx) within the health information technology infrastructure. Pharmacy 2016, 4, 2. [CrossRef]

100. Parrish, R.H., 2nd; Cernak, I. Creating a distinct medication-use system for children at the point of care: The time is now. Pharmacy 2015, 3, 72-78.

101. Ameer, B.; Weintraub, M.A. Pediatric obesity: Influence on drug dosing and therapeutics. J. Clin. Pharmacol. 2018, 58 (Suppl. 10), S94-S107. [CrossRef]

102. Horace, A.E.; Ahmed, F. Polypharmacy in pediatric patients and opportunities for pharmacists' involvement. Integr. Pharm. Res. Pract. 2015, 4, 113-126. [CrossRef]

103. Board of Pharmacy Specialties. Pediatric Pharmacy. Available online: https://www.bpsweb.org/bpsspecialties/pediatric-pharmacy/ (accessed on 17 January 2019).

104. Open University. Distributed Paradigms. Available online: https://www.open.edu/openlearn/science-mathstechnology/computing-and-ict/systems-computer/distributed-paradigms/content-section-4.2.2. (accessed on 17 January 2019).

105. Office of the National Coordinator for Health Information Technology. 'Percent of Medical Doctors e-Prescribing through an EHR on the Surescripts Network,' Health IT Quick-Stat \#1. April 2014. Available online: dashboard.healthit.gov/quickstats/pages/FIG-SS-Physicians-ERX-via-EHR-on-Surescripts. php (accessed on 17 January 2019).

106. Surescripts. Available online: https://surescripts.com/ (accessed on 11 February 2019).

107. Bureau of Labor Statistics; U.S. Department of Labor. Occupational Outlook Handbook, Physicians and Surgeons. Available online: https://www.bls.gov/ooh/healthcare/physicians-and-surgeons.htm (accessed on 17 January 2019).

108. Smart, D.R. Physician Characteristics and Distribution in the US; American Medical Association: Chicago, IL, USA, 2013.

(C) 2019 by the authors. Licensee MDPI, Basel, Switzerland. This article is an open access article distributed under the terms and conditions of the Creative Commons Attribution (CC BY) license (http://creativecommons.org/licenses/by/4.0/). 